\title{
Design and Modeling of an Integrated Octagonal Shaped Inductor with Substrate Silicon in a Buck Converter
}

\author{
Abdelhadi Namoune ${ }^{1}$, Rachid Taleb ${ }^{2}$, Noureddine Mansour ${ }^{3}$, Abdelkader Belboula ${ }^{4}$ \\ ${ }^{1}$ Electrical Engineering Department, Institute of Sciences and Technology, Ahmed Zabana University Centre, Relizane, \\ Algeria \\ ${ }^{2,4}$ Electrical Engineering Department, Hassiba Benbouali University, Chlef, Algeria Laboratoire Génie Electrique et \\ Energies Renouvelables (LGEER) \\ ${ }^{3}$ College of Engineering, University of Bahrain
}

\begin{tabular}{l}
\hline Article Info \\
\hline Article history: \\
Received Dec 31, 2018 \\
Revised Apr 30, 2019 \\
Accepted Aug 06, 2019 \\
\hline Keyword: \\
Buck converter, \\
Integration \\
Spiral inductor \\
Geometric parameters \\
Substrate
\end{tabular}

\begin{abstract}
The paper discusses the design and modeling of an integrate octagonal shaped inductor with silicon substrate. A validated equivalent electrical model of the integrated octagonal shaped spiral inductor was developed. The model was used to analyze and evaluate the quality factor and the inductance of the inductor structure proposed under different physical parameters setting. These include the number of turns, spacing between turns and the inner diameter. The simulation results show that an appropriate selection of physical parameters can achieve an enhanced quality factor and improved inductance. PSIM simulator was used for the implementation of the integrated inductor in a micro buck converter. The simulation results demonstrate that our proposals are very promising approaches for the monolithic integration of DC-DC converters.
\end{abstract}

Copyright $(2019$ Institute of Advanced Engineering and Science. All rights reserved.

\section{Corresponding Author:}

Abdelhadi Namoune,

Electrical Engineering Department,

Institute of Sciences and Technology,

Ahmed Zabana University Centre, Relizane, Algeria.

Email: nmansour@uob.edu.bh

\section{INTRODUCTION}

Modern portable electronics devices, such as cell phones, GPS (Global Positioning System) and PDA (Personal Digital Assistant), are getting smaller in size and embedding more and more features at the same time. However, these latter demands more power supply. Hence, to meet this energy demand smaller, smarter and more efficient DC-DC switching inductive converters are needed.

Switching inductive converters use inductors to transfer power from the battery to the load, which might lead to $100 \%$ efficiency in an ideal case. Theme it of these devices is that they exhibit an excellent transient performance, such as line/load regulations, without any efficiency deterioration [1-3].These switching inductive converters have gained more interest and are considered most appropriate DC-DC converters when the required power density is high and the efficiency is critical.

In modern portable electronics, such as cell phones, the power-hungry subsystems are always regulated by switching inductive converters [4-7]. Following the success in their manufacturing, intensive researches have been conducted in the modeling of spiral inductors on silicon [8]. Most research approaches opted for the use of compact circuit models [9]. These types of models are used in the synthesis and design of spiral inductors in silicon [10].

The main objective of this paper is to reduce the influence of magnetically induced losses in the inner turns of the spiral where the magnetic field reaches its maximum [11]. This can be achieved by reducing the line width toward the center of the spiral. This approach will lead to minimization of the coils inductor series resistance. Research results reported using this approach is very promising. The successful research results 
reported encouraged research for deeper studies on the device performance limitations, which will ultimately contribute to the design of improved and efficient devices.

In this paper, octagonal shaped planar spiral inductor is proposed. A simplified electrical circuit model of the inductor is developed. The relationship between technological parameters and their effect on the geometrical characteristic of the inductor are investigated. The technological parameters include the number of turns, inner diameter, width and space of the inductor. Moreover, the structure is analyzed and evaluated under different technological parameters to achieve an enhanced quality factor. This work is completed by an application of the proposed integrated inductor.

\section{DESIGN AND MODELING OF SPIRAL INDUCTOR}

For the spiral structure, there are several topological models as shown in Figure 1 [12]: In this study octagonal, geometry is selected [13-15]. Figure 2 shows a typical implementation of an integrated octagonal spiral inductor where the important physical dimensions of the spiral inductor are identified. These include inner diameter (din), outer diameter (dout), space between turns (s) and width of the metal trace (w). Table 1 indicates the specifications and the design results of the selected octagonal shape inductor.

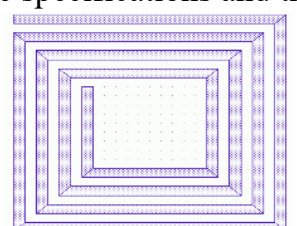

(a)

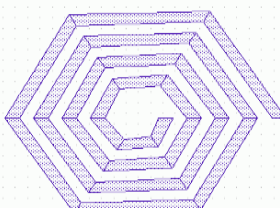

(b)

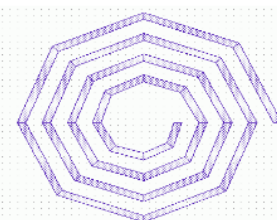

(c)

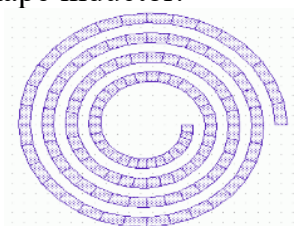

(d)

Figure 1. Different inductor geometries (a) square, (b) hexagonal, (c) octagonal, (d) circular

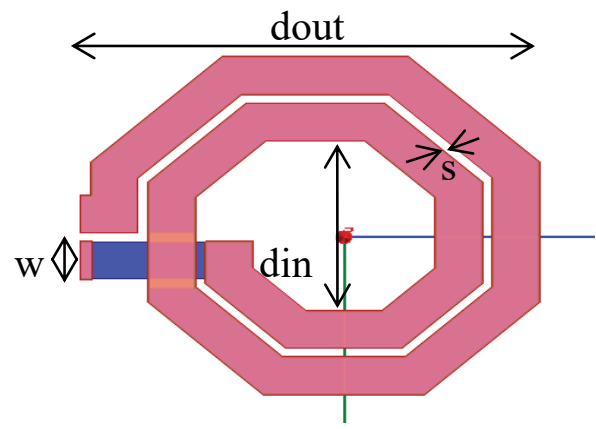

Figure 2. Typical layout of an integrated octagonal spiral inductor

Table 1. The geometrical parameters of the octagonal spiral inductor

\begin{tabular}{lcc}
\hline Geometric parameters & Symbol & Value \\
\hline Number of turns & $\mathrm{N}$ & 2 \\
Spacing between turns & $\mathrm{S}$ & $8 \mu \mathrm{m}$ \\
Width of conductor & $\mathrm{W}$ & $26 \mu \mathrm{m}$ \\
Thickness of conductor & $\mathrm{T}$ & $1,5 \mu \mathrm{m}$ \\
Inner diameter & din & $70 \mu \mathrm{m}$ \\
Outer diameter & dout & $140 \mu \mathrm{m}$ \\
\hline
\end{tabular}

In order to take into account the losses over a range of frequencies, the PI circuit model of spiral inductors on silicon depicted in Figure 3 is used. More details about the PI model used can be found in references [16-19].

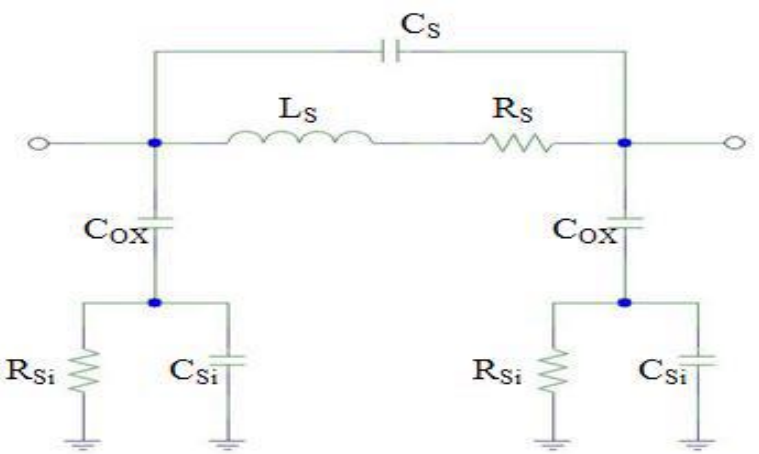

Figure 3. PI circuit equivalent model of a spiral inductor 
The different components of the PI circuit model shown in Figure 3 are defined as follows:

- $L_{s}$ is the inductance of the spiral inductor

- $R_{s}$ is the resistance of the metal trace.

- $C_{s}$ is the capacitance of the direct coupling due to the overlap between the spiral and the underpass.

- $C_{o x}$ is the oxide capacitance which represents the capacitive coupling between the inductor and the substrate through the oxide layer.

- The resistance and capacitance of the substrate, referred to ground, are represented by $\left(R_{s i}\right)$ and $\left(C_{s i}\right)$, respectively.

It is worth to mention that characteristics of each component constituting the equivalent circuit model are strongly dependent on the inductor shape as well as the technological parameters of the CMOS process used.

Several mathematical expressions are available in published literature to compute the value of inductance. In this studies the following Monomial expression is used [20]:

$$
L_{s}=\beta \cdot \mathrm{d}_{\mathrm{out}}^{\alpha 1} \cdot \mathrm{w}^{\alpha 2} \cdot \mathrm{d}_{\mathrm{avg}}^{\alpha 3} \cdot \mathrm{n}^{\alpha 4} \cdot \mathrm{s}^{\alpha 5}
$$

The monomial expression is selected because of its accuracy and simplicity to compute the inductor value. It can also be used for optimal design of spiral inductors geometric design [21].

Where $\beta$ is a layout dependent constant, $d_{\text {avg }}=\left(d_{\text {out }}+d_{\text {in }}\right) / 2$ is the average diameter of the spiral layout, $n=$ number of spiral turns, $\alpha_{i}$ where $i=1$ to 5 are the coefficients and are layout dependent. For octagonal layout $\alpha_{1}=-1.21, \alpha_{2}=-0.163, \alpha_{3}=2.43, \alpha_{4}=1.75, \alpha_{5}=-0.049$ and $\beta=1.33 \times 10^{-3}$.

The series resistance $R s$, can be approximated by the following expression [22]:

$$
R_{s}=\frac{\rho . l}{w \cdot t}
$$

Where $\rho$ and $t$ are the metal resistivity and thickness, respectively. The metal length $l$, is calculated using the following expression [23-27]:

$$
l=\left[d_{\text {out }}-(n-1) \cdot s-n \cdot w\right]-s
$$

Where dout, $n, s$ and $w$ are already defined above.

The other components of the equivalent circuit are computed using the following expressions:

$$
\begin{gathered}
C_{s}=\frac{n \cdot w^{2} \cdot \varepsilon_{o x}}{t_{o x}} \\
C_{o x}=\frac{w \cdot l \cdot \varepsilon_{o x}}{2 \cdot t_{o x}} \\
C_{s i}=\frac{1}{2} \cdot l \cdot w \cdot C_{s u b} \\
R_{s i}=\frac{2}{l \cdot w \cdot G_{s u b}}
\end{gathered}
$$

Where, $t_{o x}$ is oxide thickness between the spirals and substrate, $C_{s u b}$ is substrate capacitance per unit area, $G_{\text {sub }}$ is substrate conductance per unit area and $\varepsilon_{o x}$ is the permittivity of oxide. The other parameters are as defined above. Table 2 indicates the nominal values of the electrical parameters of the integrated inductor used in the simulation.

Table 2. Electricals parameters of the integrated inductor

\begin{tabular}{cc}
\hline Electricals Parameters & Values \\
\hline$L_{s}$ & $3,2 \mathrm{nH}$ \\
$R_{s}$ & $0,2 \Omega$ \\
$C_{s}$ & $0,0023 \mathrm{pF}$ \\
$C_{o x}$ & $0,023 \mathrm{pF}$ \\
$R_{s i}$ & $0,4 \Omega$ \\
$C_{s i}$ & $0,065 \mathrm{pF}$ \\
\hline
\end{tabular}

The simulation results are presented using the S-parameters form. The S parameters are then converted into Y parameters using following equations (8), (9), and (10) [28]: 


$$
\begin{aligned}
& Y_{11}=\frac{\left(1+S_{11}\right)\left(1+S_{22}\right)+S_{12} \cdot S_{21}}{\left(1+S_{11}\right)\left(1+S_{22}\right)-S_{12} \cdot S_{21}} \\
& Y_{12}=\frac{-2 \cdot S_{12}}{\left(1+S_{11}\right)\left(1+S_{22}\right)-S_{12} \cdot S_{21}} \\
& Y_{22}=\frac{\left(1+S_{11}\right)\left(1-S_{22}\right)+S_{12} \cdot S_{21}}{\left(1+S_{11}\right)\left(1+S_{22}\right)-S_{12} \cdot S_{21}}
\end{aligned}
$$

The electrical parameters $L$ and $Q$ are computed using equations (11) and (12) which are derived using the inductor equivalent circuit theory.

$$
\begin{aligned}
& L=\left[\left(1 / Y_{11}\right) / 2 . \pi . f\right] \\
& Q=\left[\operatorname{Im}\left(1 / Y_{11}\right) / \operatorname{Re}\left(1 / Y_{11}\right)\right]
\end{aligned}
$$

Where $f$ represents the frequency. $L, Q, Y$ represent the inductance, quality factor and admittance respectively. The symbols Im and Re represent the imaginary part and real part respectively.

\section{SIMULATION RESULT}

The performance evaluation of the spiral inductor proposed is performed using MATLAB simulation software, which allows more flexibility during the design process. In addition, the effect of spiral inductor geometry variations is more easily analyzed using MATLAB.

\subsection{Effect of Design Parameters on Quality Factor and Inductance a. Optimization of Width and Space of the Inductor}

The four inductor structures are investigated under different of values of width $(w)$ and space $(s)$ while keeping their sum the same and equal to $35 \mu \mathrm{m}$. Their respective width and space sums are $13+22 \mu \mathrm{m}, 19+16$ $\mu \mathrm{m}, 25+10 \mu \mathrm{m}$, and $29+6 \mu \mathrm{m}$. Where the first term represents the width $(w)$ and the second term represents the space $(s)$. The number of coils of the four inductors is fixed at 2 and their inner diameter is 70 um. Figure 4 shows the top view of the four structures proposed.

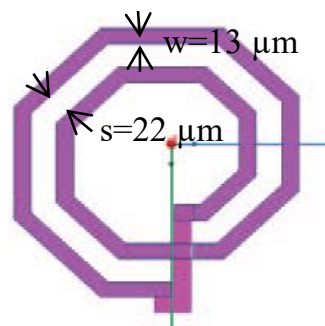

(a)

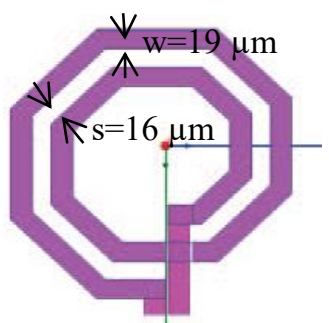

(b)

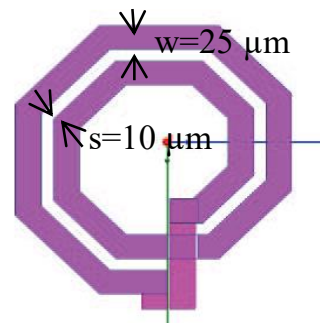

(c)

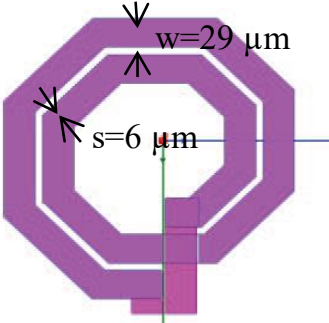

(d)

Figure 4. The top view of inductors with $(w+s)$ as (a) $13+22 \mu \mathrm{m}$, (b) $19+16 \mu \mathrm{m}$, (c) $25+10 \mu \mathrm{m}$,

(d) $29+6 \mu \mathrm{m}$

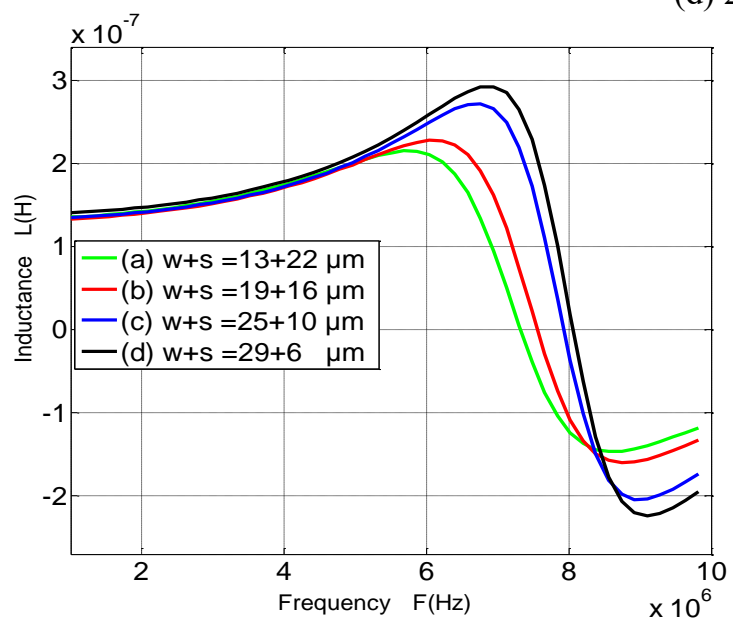

(a)

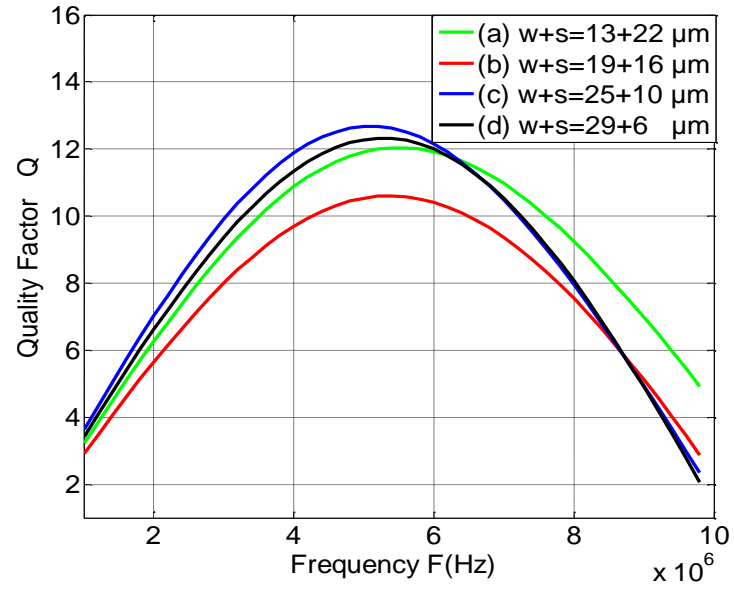

(b)

Figure 5. Effect on inductance value (a), quality factor (b) for different designs of spiral inductor 
Figure 5 shows the variation of the inductance and quality factor $\mathrm{Q}$ versus frequency of the four structures for different values of width and space. As shown in Figure 5(a) up to $5 \mathrm{MHz}$, the inductances of the four structures are not affected by the width (w) and space (s) changes and exhibit almost the same variation. However, above $5 \mathrm{MHz}$, the inductance curves appear difference because of the different parasitic capacitances, which are dependent on the width and space. The results of the quality factors obtained are shown in Figure 5(b). As shown in Figure 5 (b), the quality factors curves exhibit maximum values at frequency about $5 \mathrm{MHz}$ for different values of width and space. The largest quality factor $\mathrm{Q}$ is obtained with the structure having $25 \mu \mathrm{m}$ line width and $10 \mu \mathrm{m}$ line space about the frequency of $5 \mathrm{MHz}$.

\section{b. Effect of Number Turns}

The simulation results of the inductance and quality factor variation versus frequency for three different values of number of turns (i.e. 2, 3 and 4) are shown in Figure 6. As illustrated in Figure 6 (a), up to around $5 \mathrm{MHz}$, the inductance increases with frequency and the spiral with the highest number of turns exhibit the highest inductance. However, from Figure 6 (a), it can be deduced that the inductance value does not increase linearly with the number of turns, as the area of the inner diameter (loop area) is smaller compared to the outer diameter. The self-resonance frequency decreases significantly for each new winding added because of the increased capacitive coupling between the turns and the increased capacitive coupling to the substrate. Figure 6 (b) shows variation of the maximum quality factor versus frequency for different values of number of turns. As shown in Figure 6(b) the maximum quality factor decreases with the increasing number of turns. This is due to increased metal losses.

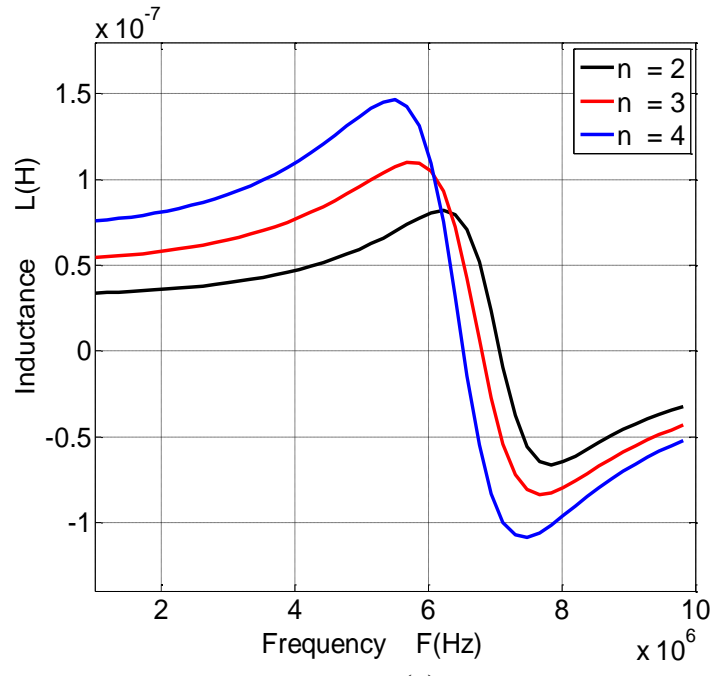

(a)

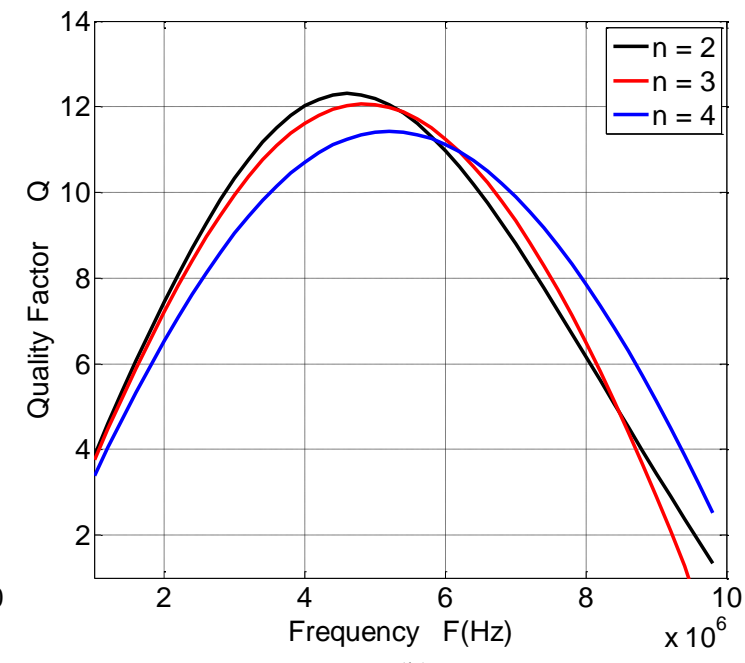

(b)

Figure 6. Effect on inductance (a), quality factor (b) value for different number of turns.

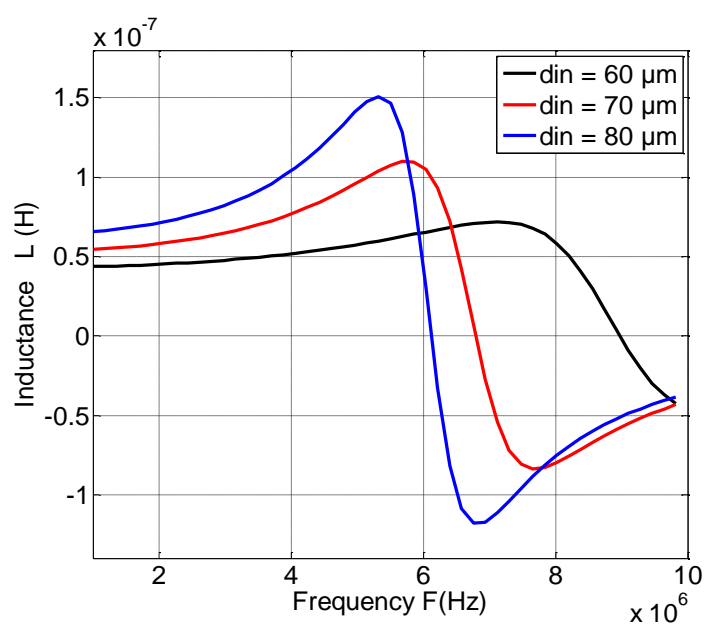

(a)

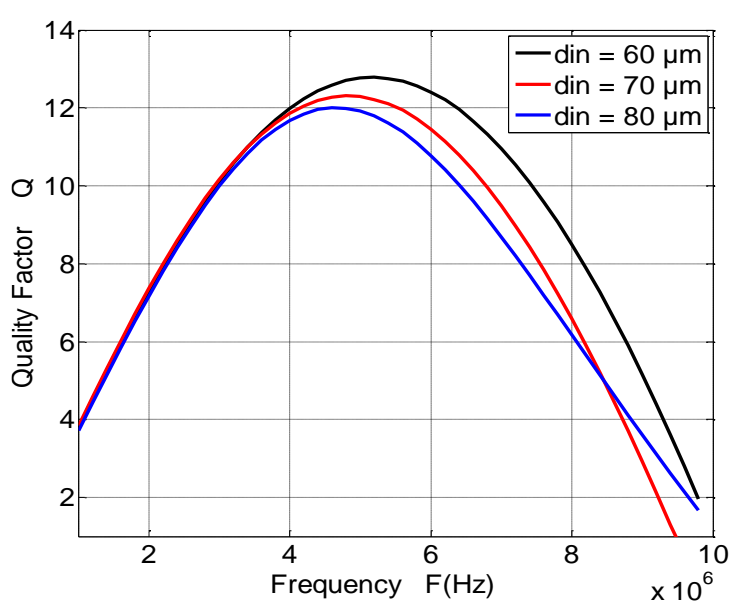

(b)

Figure 7. Effect on inductance, (a) quality factor, (b) value for different inner diameter. 


\section{c. Effect of Inner diameter}

Figure 7 shows the simulation of results of the inductance and maximum quality factor variation versus frequency for different values of inner diameter (i.e. $(60 \mu \mathrm{m}, 70 \mu \mathrm{m}$ and $80 \mu \mathrm{m})$. As shown in Figure $7(\mathrm{a})$, the inductance increases within the range of frequency and the highest increase is obtained with the highest inner diameter of $80 \mu \mathrm{m}$. However, the maximum quality factor decreases as the inner diameter increase. As shown in Figure 7(b), the highest maximum quality factor is obtained at $60 \mu \mathrm{m}$. This increase is related to the changes of the distance between opposite sides at the center of the spiral.

\subsection{Comparison with state of the art work}

Comparative studies based on the size, maximum quality factor, inductance is between previous works, and our design is summarized in Table 3 . The values of the size of inductor, maximum quality factor and inductance indicated in table under our work are derived from the parametric analysis performed.

Table 3. Comparison of different spiral inductors

\begin{tabular}{lcccc}
\hline Inductor design & Size & $\mathbf{Q}_{\max }$ & $\mathbf{L ~ ( H )}$ & Réf \\
\hline Square inductor & $380 * 500\left(\mu \mathrm{m}^{2}\right)$ & 25 & $26.10^{-9}$ & {$[29]$} \\
Hexagonal inductor & $320 * 320\left(\mu \mathrm{m}^{2}\right)$ & 53 & $24,4.10^{-9}$ & {$[30]$} \\
Circular inductor & $300 * 300\left(\mu \mathrm{m}^{2}\right)$ & 22 & $33,3.10^{-9}$ & {$[31]$} \\
Octogonal inductor & $140 * 140\left(\mu \mathrm{m}^{2}\right)$ & 12 & $75.10^{-9}$ & Our work \\
\hline
\end{tabular}

\section{BUCK CONVERTER APPLICATION}

A buck micro converter DC-DC depicted in Figure 8 is selected and PSIM software is used for its the simulation. The values of the micro converter electrical characteristics are indicated in Table 4 . The different technological parameters of the integrated inductor are calculated (Table 2) and replaced by classic inductor.

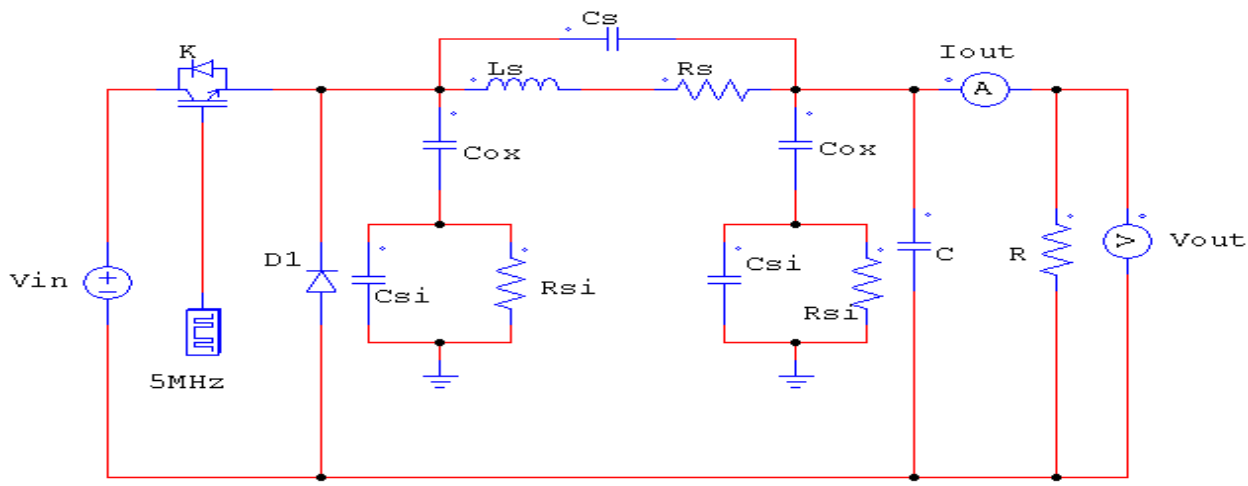

Figure 8. Schematic diagram of Buck converter DC-DC

Table 4. Design specifications of buck micro converter DC-DC

\begin{tabular}{lcc}
\hline Electrical characteristics & Symbol & Value \\
\hline Input Voltage & Vin & $3 \mathrm{~V}$ \\
Output voltage & Vout & $1.2 \mathrm{~V}$ \\
Switching frequency of the converter & $f$ & $5 \mathrm{MHz}$ \\
\hline
\end{tabular}

Figure 9 shows the waveform of the output voltage and current of the Buck converter with integrated spiral inductor. The output current simulated at the switching frequency of $5 \mathrm{MHz}$ is shown in red color. As shown in figure 9, both the output current (red line) and output voltage (blue line) of the converter are constant. The output current and voltage are settled at about $0.4 \mathrm{~A}$ and 1.2 volts respectively. It can be noticed the input voltage of $3 \mathrm{~V}$ of the converter is lowered to $1.2 \mathrm{~V}$. 


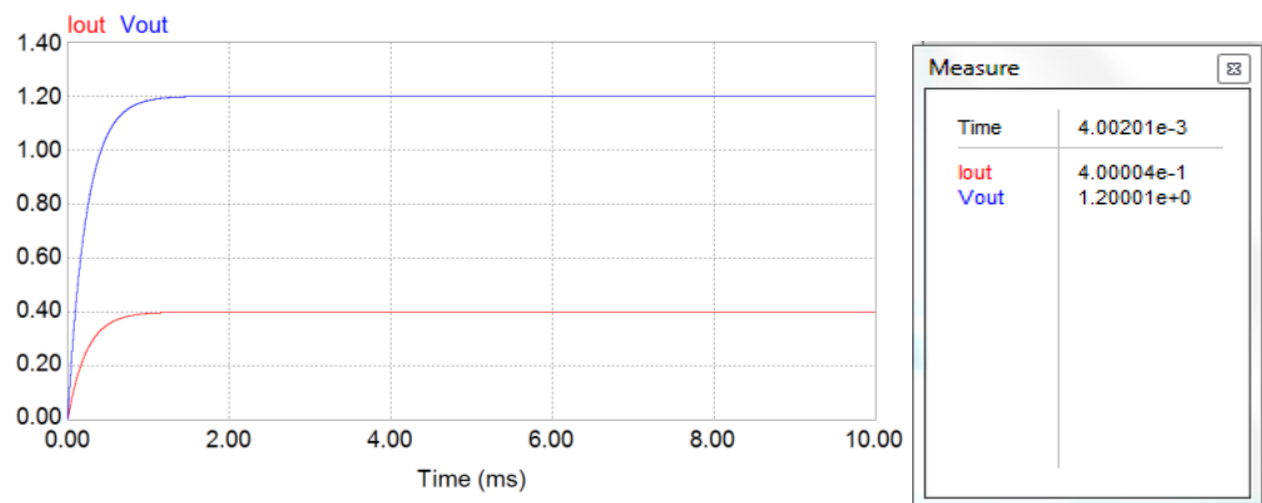

Figure 9. Output voltage and current of the Buck converter with integrated spiral inductor

\section{CONCLUSION}

In this paper, the design and modeling of an integrated spiral inductor with substrate are presented. The most challenging issues encountered were the determination of the appropriate geometrical structure and suitable technological parameters of the spiral inductor.

In this work, it was observed that the geometry of spiral inductor is an important design factor and it has a huge influence on the performance of RFIC (Radio Frequency Integrated Circuit). Moreover, it was also observed that the highest maximum quality factor of octagonal spiral inductor structures is obtained with low number of turns and low inner diameter. The simulation results of the DC-DC buck converter show that the desired value of the output voltage can be obtained.

In conclusion, it can be stated that the simulation results are very successful and demonstrate that the proposed structure of the spiral inductor is a very promising advance for the integration of buck converter.

\section{REFERENCES}

[1] S. Chunlei, B. C. Walker, E. Zeisel, B. Hu, "A Highly Integrated Power Management IC for Advanced Mobile Applications", IEEE Journal of Solid-State Circuits, 2007, vol. 42, pp. 1723-1731.

[2] J. Wibben and R. Harjani, "A High-Efficiency DC-DC Converter Using 2 nH Integrated Inductors", IEEE Journal of Solid-State Circuits, 2008, vol. 43, pp. 844-854.

[3] S. C. O. Mathuna, T. O'Donnell, W. Ningning, and K. Rinne, "Magnetics on silicon: an enabling technology for power supply on chip", IEEE Transactions on Power Electronics, 2005, vol. 20, pp. 585-592.

[4] S. Musunuri, P. L. Chapman, J. Zou, and C. Liu, "Inductor design for monolithic DC-DC converters," Conference in Proceedings of the IEEE Power Electronics Specialist, 2003, vol. 1, pp. 227- 232.

[5] T. O'Donnell, N. Wang, R. Meere, F. Rhen, S. Roy, D. O'Sullivan, and C. O'Mathuna, "Microfabricated inductors for $20 \mathrm{MHz}$ Dc-Dc converters," in Applied Power Electronics Conference and Exposition, APEC 2008. IEEE Twenty-Third Annual, 2008, pp. 689-693.

[6] D. Flynn, A. Toon, and M. P. Y. Desmulliez, "Manufacture and characterisation of micro-engineered DC-DC power converter using UV-LIGA process," Electronics Letters, 2005, vol. 41, pp. 1351-1353.

[7] S. Musunuri, P. L. Chapman, Z. Jun, and L. Chang, "Design issues for monolithic DC DC converters," IEEE Transactions on Power Electronics, 2005, vol. 20, pp. 639-649.

[8] W. Xi-Ning, Z. Xiao-Lin, Z. Yong, D. Xu-Han, C. Bing-Chu, "Fabrication and performance of novel RF spiral inductors on silicon", Microelectronics Journal, vol. 36, no. 8, pp. 737-740, August 2005.

[9] N. Badr, E. Ahmed, Z. Jamal, T. Abdelali, E. Larbi, L. Mohamed, "A Compact Planar Low-Pass Filter Based on SRR-Metamateria”, International Journal of Electrical and Computer Engineering (IJECE), vol. 8, no. 6, December 2018 (Part II).

[10] R. Manikandan, V. Venkata, C. Anjan, A. Bharadwaj, "A parameterized cell design for high-Q, variable width and spacing spiral inductors", IEEE International Microwave and RF Conference (IMaRC), Bangalore, India, 15-17 Dec. 2014.

[11] J. N. Burghartz, Fellow, IEEE, and Behzad Rejaei, "On the Design of RF Spiral Inductors on Silicon," IEEE Transactions On Electron Devices, 2003, vol. 50, no. 3.

[12] M. Wang, I. Batarseh, K. D. T. Ngo, and H. Xie, "Design and Fabrication of Integrated Power Inductor Based on Silicon Molding Technology," Conference IEEE in Power Electronics Specialists, PESC 2007, pp. 1612-1618.

[13] P. Almeida, P. Pereira, and M. H. Fino, "Using variable width rf integrated inductors for quality factor optimization", the Internet of Things in Technological Innovation for Springer Berlin Heidelberg, 2013, vol. 394, pp. 619-627.

[14] J. Chen and J. J. Liou, "On-chip spiral inductors for rf applications: An overview", Journal of Semiconductor Technology and Science, 2004, vol. 4, no. 3, pp. 149-167.

[15] J. Liu, Y. Shi, X. Wen, D. Chen, et al., "On chip spiral inductor with novel gradually changed structure," Microwave and Optical Technology Letters, 2008, vol. 50, no. 8, pp. 2210-2213, 
[16] S. S. Mohan, Maria del Mar Hershenson, S. P. Boyd, and T. H. Lee, "Simple Accurate Expressions for Planar Spiral Inductances”, IEEE Journal Of Solid-State Circuits, 1999, Vol. 34, No. 10.

[17] P. Pirouznia and Bahram Azizollah Ganji, “Analytical Optimization of High Performance and High Quality Factor MEMS Spiral Inductor,” Progress In Electromagnetics ResearchM, 2014, Vol. 34, 171-179.

[18] J.-T. Kuo, K.-Y. Su, T.-Y. Liu, H.-H. Chen, and S.-J. Chung, "Analytical calculation for dc inductances of rectangular spiral inductors with note metal thickness in the peek formulation," IEEE Microwave and Wireless Components Letters, 2006, Vol. 16, No. 2, 69-71.

[19] K. Itoi, M. Sato, K. Okada, K. Masu, dan T. Ito, "Comparison of compact on-chip inductors embedded in waferlevel package", 55th Conference in Electronic Components and Technology, 2005, vol. 2, p. 1578-1583.

[20] C. Patrick Yue, S. Simon Wong, et al., "Physical Modeling of Spiral Inductors on Silicon", IEEE Transactions On Electron Devices, 2000, vol. 47, no. 3.

[21] A. Namoune, A. Hamid, R. Taleb, "The performance of an integrated transformer in a DC/DC converter," TELKOMNIKA, 2017, vol. 15, pp. 1031-1039

[22] V. N. R. Vanukuru and A. Chakravorty, "Integrated layout optimized high-g inductors on high-resistivity SOI substrates for RF front-end modules", International Conference on Signal Processing and Communications (SPCOM), 2014, p. 1-5.

[23] Kanad Mallik, A. Abuelgasim, et al., "Analytical and numerical model of spiral inductors on high resistivity silicon substrates ," ELSEVIER, Solid-State Electronics, 2014, vol. 93 pp. 43-48,

[24] V. N. R. Vanukuru and A. Chakravorty, "Design of Novel High-Q Multipath Parallel- Stacked Inductor", IEEE Trans. Electron Devices, 2014, vol. 61, no 11, p. 3905-3909.

[25] Cong Wang, Nam-Young Kim., "Analytical optimization of highperformance and high-yield spiral inductor in integrated passive device technology," Microelectronics Journal,2012, vol. 43, pp.176-181.

[26] F. Z. Medjaoui, A. Hamid, Y. Guettaf, P. Spiteri, and V. Bley, "Conception and manufacturing of a planar inductance on NiFe substrate," Transactions on Electrical and Electronic Materials, 2019

[27] H. Kharbouch, A. Hamid, et al., "Using the variable width in a planar inductor on Kapton for optimizing its performance," Turkish Journal of Electrical Engineering \& Computer Sciences, 2017, vol. 25, pp. 3798-3810

[28] A. Allaoui, A. Hamid, P. Spiteri, V. Bley, T. Lebey, "Thermal modeling of an integrated inductor in a microconverter," J. Low Power Electron, 2015, vol.11, pp. 63-73.

[29] Y. Benhadda, A. Hamid, T. Lebey, A. Allaoui, M. Derkaoui, R. Melati, "Thermal Behavior of an Integrated Square Spiral Micro Coil,” TELKOMNIKA Indonesian Journal of Electrical Engineering, 2015, vol. 14, pp. 250 - 265.

[30] M. B. Pisani, S. Bantas, C. Hibert, et al., "High-Q inductors for $1-10 \mathrm{GHz}$ applications: modeling, simulation, design and fabrication", in Proceedings of the 4th Workshop on MEMS for Millimeter-Wave Communications (MEMSWAVE'03), Toulouse, France, July 2003, pp. B7.

[31] Y. Benhadda, A. Hamid and T. Lebey, "Dimensioning and Modeling of a Circular Inductor Integrated in a Boost Converter," Journal of Nano- and Electronic Physics, 2016, vol. 8, pp. 4039(5). 